\title{
PRISTUP RIZICIMA U SISTEMU MENADŽMENTA KVALITETA ZASNOVAN NA FMEA METODI
}

\author{
RISK ASSESSMENT IN QUALITY MANAGEMENT SYSTEM \\ BASED ON THE FMEA METHOD
}

\author{
Ana ČOBRENOVIĆ ${ }^{1)}$, Mladen ĐURIĆ ${ }^{2)}$, \\ ${ }^{1)}$ MPC Holding, Beograd; \\ ${ }^{2)}$ Fakultet organizacionih nauka, Beograd \\ ana.cobrenovic@mpcholding.com; djuricm@fon.bg.ac.rs
}

\begin{abstract}
Pristup menadžmentu rizika varira u zavisnosti od delatnosti $i$ veličine organizacije, te se može posmatrati iz mnoštva različitih aspekata. Na svakoj organizaciji je da prepozna svoje rizike i prilike, kao i da se na adekvatan način bavi njima. Savremena poslovna praksa pokazuje koliko je ovaj koncept važan za uspešno poslovanje i funkcionisanje bilo koje organizacije. U tom smislu, razmišljanje zasnovano na riziku postaje nezaobilazni princip i deo standarda za sisteme menadžmenta. Način tumačenja zahteva ovih standarda predodređuje alate i metode menadžmenta rizika koje jedna organizacija koristi. U ovom radu se daje tumačenje zahteva standarda ISO 9001:2015 za sisteme menadžmenta kvaliteta, koji su u vezi sa menadžmentom rizika, kao i neka od rešenja zasnovana na procesnom pristupu, u kombinaciji sa primenom FMEA metode. Ovakav pristup pruža izvrsnu osnovu za povećanje efektivnosti sistema menadžmenta kvaliteta, ostvarivanje poboljšanih rezultata, kao i sprečavanje negativnih efekata.
\end{abstract}

Ključne reči: Sistem menadžmenta kvaliteta; menadžment rizika; procesni pristup; ISO 9001:2015; FMEA

Risk management approach varies depending on activity and size of the organization, and can be achieved from many different aspects. Organization should recognize and properly address its risks and opportunities. Nowadays, business practice shows that this concept is important for successful business and operations of any organization. Furthermore, risk-based thinking is becoming an essential principle of management system standards. Risk management tools and methods that organizations should use depend on the adequate interpretation of these standards requirements. This paper presents an interpretation of the ISO 9001: 2015 requirements for the quality management systems, that are related to risk management, as well as some of the solutions based on the process approach combined with the use of FMEA method. This approach provides an excellent basis for enhancing the effectiveness of the quality management system, improving process results, and preventing negative effects. FMEA

Key words: Quality management system; risk management; process approach; ISO 9001:2015;

\section{Uvod}

Rizik je pojam koji oduvek postoji u našem okruženju, kao stanje u kome je moguće neželjeno odstupanje od ishoda kojem se nadamo. Za današnje poslovanje, takvo stanje je neizbežno. U uslovima velike ponude proizvoda i usluga na svetskom tržištu, zadovoljstvo korisnika predstavlja najbitniji faktor koji oblikuje proizvode i usluge. Mera zadovoljstva korisnika je kvalitet, a efektivan menadžment rizika u okviru poslovanja čini da je kvalitet stalno obezbeđen.

Ovaj rad najpre objašnjava univerzalne faze menadžmenta rizika. Faze omogućavaju lakše snalaženje u svim aktivnostima koje je neophodno sprovesti kako bi rizici bili identifikovani i tretirani na pravi način.

Da bi se princip razmišljanja zasnovanog na riziku potpuno razumeo, najpre se treba upoznati sa načinima na koji je rizik bio posmatran u prethodnim verzijama standarda ISO 9001. U vremenskom periodu od skoro tri pune decenije, pristup rizicima se značajno menjao, dok nije dostigao današnji sveobuhvatan oblik. Ovaj rad predstavlja viđenje rizika u svim prethodnim verzijama standarda za sisteme kvaliteta, i detaljnu analizu principa razmišljanja zasnovanog na riziku kao jedan od najvažnijih principa aktuelne verzije standarda. 
$\mathrm{Na}$ osnovu iskustva eksperata i organizacija, može se zaključiti da je najširu primenu u praksi menadžmenta rizika kroz sisteme menadžmenta kvaliteta u organizacije, imala analiza načina, efekata (i kritičnosti) otkaza (FMEA - Failure Mode and Effect Analysis). M. Vujošević [1]

FMEA metoda u kombinaciji sa drugim alatima, analizama sistema, zahtevima standarda i primenom principa kvaliteta, kao što je procesni pristup, pruža jednostavan i sistematičan način za bavljenje rizicima u bilo kojoj organizaciji.

\section{Menadžment rizika i prethodne verzije standarada ISO 9001}

Predviđanje mogućih ishoda bilo koje aktivnosti je ključni deo procesa racionalnog upravljanja i odlučivanja. Danas, sve organizacije bez obzira na delatnost i veličinu, konstantno se susreću sa nekom formom rizika,bilo da je on u vezi sa proizvodima, uslugama, projektima ili strateškim potezima.Upravljanje rizikom se bavi mogućim nepovoljnim, ali i povoljnim ishodima na naučan i organizovan način radi otklanjanja ili umanjenja šanse da se dogode štete ili gubici u poslovanju. [1]

Koraci koje menadžment rizika podrazumeva različiti autori definišu kroz različite pristupe. Na primer: postavljanje i definisanje ciljeva, predviđanje, planiranje sa odlučivanjem, pribavljanje resursa, organizovanje, motivisanje i instruisanje, realizacija, koordinacija, adaptacija i učenje [1]; ili na primer: identifikacija, analiza i upravljanje rizika. Đapić, M., Lj. Lukić, V. Kilibarda [2]

Kod svakog pristupa se u osnovi, za potrebe ovog rada,mogu izdvojiti sledeći procesi:

- identifikacija rizika,

- analiza i rangiranje rizika,

- upravljanje rizika i

- praćenje rizika.

\subsection{Identifikacija rizika}

Identifikacija rizika je početna i ujedno najteža faza menadžmenta rizika. Ova faza se literarno može opisati izrazom „otvorite četvoro očiju“. Spoznati sve moguće, pa čak i nemoguće, iznenađujuće i vanredne situacije do kojih može doći u toku poslovnih procesa, uopšte nije lak zadatak.

Identifikacija rizika ne podrazumeva samo identifikaciju nepredviđenih negativnih situacija i njihove mogućnosti realizacije, već i povoljnih prilika koje mogu nastati prihvatanjem nekog identifikovanog rizika. Što više prepoznatih potencijalnih ishoda, to bolje.

S obzirom da je identifikacija rizika delom subjektivna, ukoliko se previše posvetimo detaljima nekog procesa, mogu se ispustiti neki očigledni, veliki rizici. Zato treba identifikovati rizike u odnosu na interno i eksterno okruženje organizacije, što podrazumeva identifikaciju interesnih i zainteresovanih strana.

\subsection{Analiza i rangiranje rizika}

Korak analize i rangiranja rizika obično se sastoji iz dodeljivanja kvantifikovanih vrednosti identifikovanim rizicima. Potrebno je da se rizici i prilike klasifikuju u odnosu na interno i eksterno okruženje organizacije.

Interno okruženje se obično odnosi na ono što je organizacija definisala kroz svoje vrednosti, misiju, viziju i kulturu organizacije, ali i sve vrste resursa, uključujući i ljudske resurse kao jednu od glavnih internih zainteresovanih strana, dok se eksterno okruženje odnosi na sve faktore (tehnološke, ekonomske, regulatorne, sociološke, ekološke, i političke) i zainteresovane strane iz okruženja organizacije.

Takozvano merenje rizika vrši se uz pomoć određenih alata uz pomoć kojih se uglavnom dodeljuju ocene verovatnoće i ocene posledice odvijanja neželjenog ili neplaniranog događaja. Bez merenja rizika nije moguće preći na fazu upravljanja rizikom, jer za potrebe upravljanja mora postojati osnova za postavljanje ciljeva koje treba ispuniti.

\subsection{Upravljanje rizika}

Upravljanje rizika treba da odgovori na sledeća pitanja: Kako pozitivni efekti mogu biti ojačani? Kako se mogu smanjiti ili sprečiti neželjeni efekti na željeni rezultat? U ovu svrhu se preduzimaju određene mere za rangirane identifikovane rizike.

Rizik se može eliminisati putem eliminacije mogućnosti nepoželjnog ishoda događaja, ili barem smanjiti preduzimanjem mera za smanjenje mogućnosti dešavanja takvog događaja. S obzirom da 
skoro nikada ne postoji apsolutna zaštita od nezgode, treba pronaći načine da se smanje posledice ako se ona ipak dogodi. Rizik je nekada moguće podeliti ili ga preneti na druge prenosom odgovornosti za realizaciju potencijalnog neželjenog događaja. Koliko god se trudili da otklonimo pretnje, neke ostaju i na kraju se postavlja pitanje da li rizik treba prihvatiti.

Za donošenje svih navedenih odluka kao pomoć se koriste određeni alati i metode koji će biti detaljnije razmotreni u daljem toku ovog rada.

\subsection{Praćenje rizika}

Ovaj korak treba da odgovori na pitanje kako organizacija vrednuje efektivnost mera preduzetih u fazi upravljanja rizikom i kako organizacija može ostvariti stalno poboljšavanje u tretmanima rizika. Takođe, bitno je reći da se prva faza, identifikacija rizika, ne zaustavlja samo na utvrđivanju rizika i rizičnih situacija pre početka izvođenja pojedinih aktivnosti. Kontrola i praćenje rizika se odnosi na identifikaciju novih i praćenje statusa starih rizika kako se ne bi ponovo pojavili.

U toku realizacije svakog od navedenih koraka treba biti na oprezu, i uvek na umu imati poznati Marfijev zakon: „ako stvari mogu ići loše, ići će loše“. Iz tog razloga upravljanje rizikom je veoma važan deo sistema menadžmenta kvaliteta. Osnovno je proučiti uzroke koji bi mogli dovesti do neželjenih ishoda, i u što većoj mogućoj meri ih ukloniti. Naravno ukoliko je reč o prilikama, njih treba maksimizirati.

\subsection{Aspekti rizika u prethodnim verzijama standarda}

Prva verzija standarda za sisteme menadžmenta kvaliteta iz 1987. godine (ISO 9000: 1987) je imala istu strukturu kao britanski standard VS 5750. Standard je obuhvatao tri „modela" za sisteme menadžmenta kvaliteta, koji su se primenjivali na osnovu obima aktivnosti organizacije. Sa strukturom od dvadeset „elemenata“ $\mathrm{t}$. zahteva, naglasak je bio na usaglašenosti sa definisanim procedurama, a manje na procesu upravljanja. Samim tim, elementi rizika su se mogli samo nazirati kroz izbegavanje neželjenih situacija u poslovanju kroz poštovanje procedura. The British Assesment Bureau [3]

Verzija iz 1994. godine je bila pokušaj da se standard probije do većeg broja organizacija i pojednostavi jezik standarda iz 1987. Procesni pristup je bolje objašnjen, a aspekti rizika se u ovoj verziji naziru kroz kontrolu procesa i samim tim, po prvi put, planiranje korektivnih i preventivnih aktivnosti za potrebe obezbeđenja kvaliteta. Ovim je počelo predviđanje potencijalnih problema u vezi kvaliteta poslovanja, što se može definisati kao jedan od elemenata rizika. [3]

U sledećoj verziji standarda, ISO 9001:2000, dogodile su se radikalne promene i procesni pristup se po prvi put našao u osnovi standarda kao jedan od osam osnovnih principa menadžmenta kvaliteta. Najveći pomak ka uvođenju menadžmenta rizika napravljen je zahtevom za postojanje dokumentovane procedure za definisanje preventivnih mera. Takođe, ova verzija sadržala je i zahtev za postojanjem dokumentovane procedure za korektivne mere. Ovim putem, znatno se smanjila mogućnost nastanka štete i nezadovoljstva korisnika i standard je doživeo veliku ekspanziju na svetskom tržištu.

Korektivne i preventivne mere, predstavljaju preduslov za poboljšavanje kvaliteta i stabilnosti sistema. Potreba za korektivnim merama nastaje u slučaju pojave interne neusaglašenosti (proizvoda, usluga ili sistema menadžmenta kvaliteta) ili iz spoljašnjih izvora. Samim tim, ove mere su namenjene traj eliminaciji uzroka i nastalih posledica problema, koji mogu imati negativan uticaj na organizaciju. J. Filipović, M. Đurić [4]

Preventivne mere sprečavaju pojavljivanje neusaglašenosti, odnosno namenjene su predupređivanju nastanka potencijalnih problema koji mogu imati negativan uticaj na poslovne rezultate organizacije, proizvode, procese, usluge, sisteme menadžmenta kvaliteta ili zadovoljenje korisnika. Preventivna mera, sama po sebi, ne predstavlja poboljšanje, ali je preduslov za poboljnjavanje kvaliteta [4]

Četvrta revizija standarda (ISO 9001:2008) izašla je 14. novembra 2008. godine. Ova revizija je sadržala manje izmene u odnosu na prethodnu. Cilj je bio da se razjasne postojeći zahtevi i da se poboljša usklađenost strukture standarda sa standardima za druge sisteme menadžmenta. Ova verzija je takođe zahtevala dokumentovane procedure za korektivne i preventivne mere. ISO [5]

\section{Koncept razmišljanja zasnovanog na riziku u standaradu ISO 9001:2015}

Standard ISO 9001 je za 29 godina pretrpeo ukupno četiri revizije. 2015. godine došlo je vreme za novu, petu reviziju, koja je donela mnoga značajna osveženja u svet kvaliteta. Pored novosti kao što 
su kontekst organizacije, pojam dokumentovanih informacija, liderstvo, znanje organizacije i slično, najveći izazov je bilo upravo kreiranje koncepta razmišljanja zasnovanog na riziku.

Reč „rizik“, prilikom kreiranja nove verzije standarda, izazvala je mnoge probleme. Jedan od ciljeva standarda bio je da se istaknu prilike koje rizik može da stvori za organizaciju. Veliki problem je predstavljalo i pitanje da li treba obuhvatiti dobre i loše posledice različitih situacija istim procesima menadžmenta. Komitet se složio da usvoji termin „rizik“, ali sa detaljnijim pojašnjenjima njegovog značenja. Da li je rečenica: „Veliki je rizik da ću dobiti na lutriji.“ smislena? Jeste, jer postoji neizvesnost dobitka na lutriji. Ishod dobitka može da bude pozitivan i da omogući finansijsku sigurnost, ali može biti i negativan, jer možete postati meta kriminalaca. F. Francis [6]

Standard ISO 9000:2015 - Sistemi menadžmenta kvalitetom - Osnove i rečnik, definiše rizik kao „posledicu neizvesnosti“. Napomene u definiciji dalje opisuju rizik kao „odstupanje od očekivanog", bilo da je ono pozitivno ili negativno. ISO [7]

Nova verzija međunarodnog standarda specificira zahteve za organizaciju da razume sopstveni kontekst i da utvrđuje rizike kao osnovu za planiranje. To predstavlja primenu „razmišljanja zasnovanog na riziku". Jedna od ključnih namena sistema menadžmenta kvalitetom jeste da deluje kao preventivni ,alat”. Zbog toga, ovaj međunarodni standard nema posebnu tačku ili podtačku o preventivnoj meri, već se izražava novim konceptom razmišljanja zasnovanog na riziku. [7]

U standardu ISO 9001:2015, zahtevi koji se odnose na rizike i prilike, prožimaju se kroz sve tačke standarda u većoj ili manjoj meri. U nastavku su nabrojana sva mesta u standardu na kojima se spominju rizici i prilike:

Tabela 1 - Tačke standarda ISO 9001:2015 koje se odnose na rizike

\begin{tabular}{|l|l|l||}
\hline \multicolumn{1}{|c|}{ Tačka } & \multicolumn{1}{|c|}{ Naslov tačke } & \multicolumn{1}{|c|}{ Objašnjenje } \\
\hline \hline 0.3 .3 & Uvod - Razmišljanje zasnovano na riziku & Opisuje koncept razmišljanja zasnovanog na riziku. \\
\hline 4.1 & Razumevanje organizacije i njenog konteksta & $\begin{array}{l}\text { Na ovu tačku se direktno poziva zvanični zahtev za } \\
\text { mere koje se tiču rizika i prilika. }\end{array}$ \\
\hline 4.2 & $\begin{array}{l}\text { Razumevanje potreba i očekivanja zainteresovanih } \\
\text { strana }\end{array}$ & $\begin{array}{l}\text { Na ovu tačku se direktno poziva zvanični zahtev za } \\
\text { mere koje se tiču rizika i prilika. }\end{array}$ \\
\hline 5.1 .1 & Liderstvo - Opšte & $\begin{array}{l}\text { Zahteva se promovisanje koncepta razmišljanja bazira- } \\
\text { nog na riziku u celoj organizaciji od strane najvišeg } \\
\text { rukovodstva. }\end{array}$ \\
\hline 5.1 .2 & Usredsređenost na korisnika & $\begin{array}{l}\text { Zahteva se utvrđivanje rizika koji utiču na usaglašenost } \\
\text { proizvoda/usluge od strane najvišeg rukovodstva. }\end{array}$ \\
\hline 6.1 & Mere koje se odnose na rizike i prilike & Odnosi se direktno na rizike i prilike. \\
\hline 7.1 & Resursi & $\begin{array}{l}\text { Organizacija je u obavezi da utvrdi i obezbedi neopho- } \\
\text { dne resurse uzimajući u obzir pripadajuće rizike i } \\
\text { ograničenja. }\end{array}$ \\
\hline 8.5 .1 & Upravljanje proizvodnjom i pružanjem usluga & $\begin{array}{l}\text { Zahteva se primena mera za sprečavanje ljudskih } \\
\text { grešaka. }\end{array}$ \\
\hline 9.3 & Preispitivanje od strane rukovodstva & $\begin{array}{l}\text { Eksplicitno zahteva utvrđivanje efektivnosti mera koje } \\
\text { se odnose na rizike i prilike. }\end{array}$ \\
\hline 10.2 & Neusaglašenost i korektivna mera & $\begin{array}{l}\text { Zahteva da organizacija, ukoliko je neophodno, pono- } \\
\text { vo preispituje i ažurira rizike i prilike koje je utvrdila. }\end{array}$ \\
\hline
\end{tabular}

\section{Primena FMEA metode u menadžmentu rizika}

Da bi se verovatnoća pojavljivanja nezgode smanjila, najpre treba proučiti mehanizme pojavljivanja grešaka, a zatim razumeti načine, efekte i posledice ostvarenja pretnji. Široko primenjivan alat $u$ ovom slučaju jeste Analiza načina, efekata (i kritičnosti) otkaza (FMEA -Failure Mode and Effect Analysis) koja je krajem šezdesetix godina ovog veka razvijena i formalizovana u okviru američkog programa „Apolo“. T. Vukčević, Z. Rajić [8]

Kratkoročno, FMEA daje spisak potencijalnih otkaza, identifikuje ozbiljnost njihovih efekata i određuje prioritet akcija korekcije. Dugoročno, FMEA razvija kriterijume za planiranje testiranja sistema, osigurava dokumentaciju za buduće analize pouzdanosti u slučaju izmene sistema, osigurava 
osnovu za planiranje održavanja, kao i za kvalitativnu i kvantitativnu analizu pouzdanosti sistema. K. Buntak, I. Drožđek, M. Košćak [9]

Cilj ove analize je da omogući pravovremeno otkrivanje i lokalizovanje mogućih grešaka na proizvodu, usluzi ili procesu, da spreči ili ublaži rizike u okviru projekata, da spreči nepotrebne troškove škarta ili drugih grešaka, pa čak i da spreči gubitak imidža na tržištu. Kao osnov za ocenu rešenja razmatraju se moguće greške $u$ vezi sa relevantnim sistemskim procesom i verovatnoća pojave potencijalne greške, moguće posledice greške, kao i mogućnosti otkrivanja i sprečavanja greške pre nego što ona stigne do kupca. [8]

\subsection{FMEA i identifikacija rizika}

Kada se koristi FMEA kao osnovni alat za menadžment rizika, u fazi identifikacije moguće je pridružiti joj još neke metode. Identifikacija rizika, počinje identifikacijom zainteresovanih strana.

Zainteresovane strane su svi pojedinci ili grupe prepoznati od strane organizacije kao neko ko ima legitimne interese u očuvanju, menadžmentu i korišćenju resursa i potencijala. Kategorije zainteresovanih strana su zajedničke za mnoge situacije i mogu da imaju i suprotstavljene interese (ekonomske/obrazovne, očuvanje/iskorišćavanje, student/profeor, zaposleni/poslodavac). J. Filipović, M. Đurić [10]

Kada su zainteresovane strane identifikovane, potrebno je pridružiti im pripadajuće rizike. Ovaj korak je delom kreativan, tako da se u ove svrhe mogu koristiti i metode kao što su SWOT, PEST, brainstorming, kreiranje različitih matrica rizika, ali i benchmarking. Ključno za efektivnu implementaciju sistema menadžmenta kvaliteta je identifikovane rizike potom povezati sa utvrđenim poslovnim procesima organizacije kako bi mogla da usledi detaljna analiza rizika.

Za početak, najjednostavniji način za primenu FMEA metode je kreiranje tabele koja sadrži spisak svih poslovnih procesa kojima će se kasnije priključiti odgovarajući rizici.

\subsection{FMEA - analiza i rangiranje rizika}

Korak analize i rangiranja rizika je ključan kada je primena FMEA alata u pitanju. Svakom identifikovanom riziku je potrebno dodeliti ocenu, koja se dobija posebnim vrednovanjem verovatnoće nastanka rizika, vrednovanjem ozbiljnosti posledice ukoliko se neželjeni događaj, koji rizik iskazuje, dogodi, i vrednovanjem detektabilnosti tj. mogućnosti identifikacije nastanka neželjenog događaja. Proizvod dobijenih ocena čini konačnu ocenu određenog rizika. Što je ocena veća, rizik je ozbiljniji i što pre mu treba posvetiti pažnju.

U ovom koraku je najvažnije jasno utvrditi obim skale i značenje ocena. Na primer, kada se vrednuje verovatnoća nastanka neželjenog događaja, najniža ocena treba da opisuje da je verovatnoća minimalna ili mala. Radi lakšeg snalaženja, organizacije mogu kreirati sopstvena uputstva sa značenjem ocena koja se, po pitanju verovatnoće nastanka, mogu bazirati na opisu konkretnog uzroka nastanka, ili na učstalosti pojavljivanja navedenog neželjenog događaja u prošlosti.


Slika 2 - Primer ocene rizika prema učestalosti događanja

Lako je zaključiti da je na sličan način moguće oceniti i ozbiljnost posledice događanja, za koju takođe važi pravilo - što veća ocena, to ozbiljnija posledica neželjenog događaja na poslovni sistem. 
Kada je detektabilnost u pitanju, značenje ocene je suprotno. To znači da što je ocena veća, mogućnost detektovanja neželjenog događaja je manja. O ovome posebno treba voditi računa, jer ukoliko se ocene ne dodele na pravi način, konačni rezultat i rang rizika neće biti validni i adekvatne mere za ublažavanje rizika neće biti primenjene pravovremeno.

Kada se sve tri ocene dodele svim identifikovanim rizicima, ocene se množe kako bi se dobila konačna, i prelazi se na sledeći korak. Konačna ocena se naziva RPN - Risk Priority Number.

\subsection{FMEA i upravljanje rizika}

Rizici koji imaju najveći RPN imaju prioritet u definisanju mera koje će ih ublažiti. Jedan od načina za adekvatno određivanje prioritetnih rizika je da organizacije jasno definišu granice vrednosti za RPN. Za ovaj korak, poželjno je okupiti zaposlene i eksperte različitih ekspertiza kako bi se došlo do adekvatnih rangova za RPN. Na primer, organizacija može odlučiti da prioritet imaju rizici kojima je RPN veći od 50, ili da sve rizike kojima je vrednost RPN između 0 i 10 prihvata i ne preduzima nikakve mere, ali ih jednom godišnje svakvko ponovo preispituje.

Mere koje će organizacija primeniti kako bi ublažila postojeće rizike, poželjno je da osmišljavaju vlasnici odgovarajućih procesa i svi ostali zaposleni čije aktivnosti mogu imati uticaja na njegovo ublažavanje. U ovoj fazi se mogu koristiti dodatne metode kao što su: RCA (Root Cause Analysis), Cost-Benefit analiza, Ishikawa dijagram i mnoge druge.

U ovom koraku se ispoljava kreativnost i sposobnost organizacija da prepoznaju preventivne mere za identifikovane rizike i pravovremeno reaguju kako bi održale kontinuitet svog poslovanja.

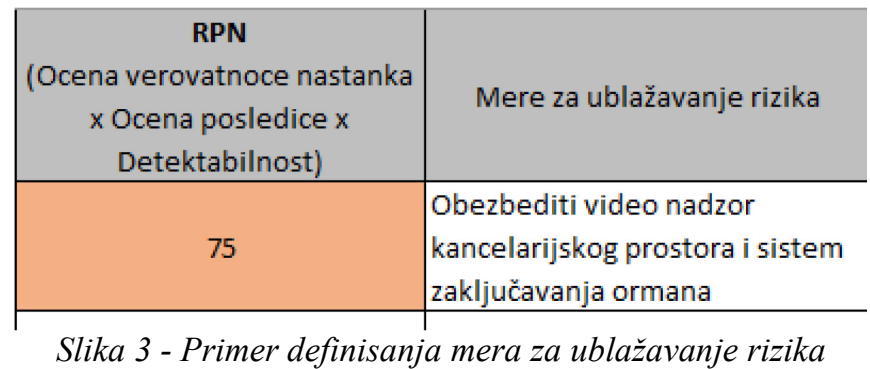

\subsection{FMEA i praćenje rizika}

Svaka definisana mera, po svojoj prirodi, teži preispitivanju. Kada se utvrđena mera sprovede, sistem zahteva da se njen efekat proveri i, ukoliko je potrebno, primeni drugačija mera. Poželjno je da postoji dodatni dokument ili produženje postojeće FMEA tabele, gde se evidentira efekat sprovedenih mera i ponovno ocenivanje rizika, kako bi rizici dobili priliku da smanje svoj RPN vrednost u budućnosti.

Učestalost ove aktivnosti može biti propisana kao godišnja, kvartalna ili, po svakoj sprovedenoj meri. Sistem menadžmenta kvaliteta, kroz ponovno ocenjivanje rizika i evaluaciju mera, na ovaj način obezbeđuje svoju sledljivost i težnju ka stalnom unapređenju.

\begin{tabular}{c|l|l|r|r|r}
$\begin{array}{c}\text { RPN } \\
\text { (Ocena verovatnoce nastanka } \\
\text { x Ocena posledice } \mathrm{x} \\
\text { Detektabilnost) }\end{array}$ & Mere za ublažavanje rizika & $\begin{array}{c}\text { Datum } \\
\text { sprovođenja mere }\end{array}$ & $\begin{array}{c}\text { Ocena } \\
\text { verovatnoce } \\
\text { nastanka }\end{array}$ & $\begin{array}{c}\text { Ocena } \\
\text { posledice }\end{array}$ & Detektabilnost \\
75 & $\begin{array}{l}\text { Obezbediti video nadzor } \\
\text { kancelarijskog prostora i sistem } \\
\text { zaključavanja ormana }\end{array}$ & 20.4 .2017$. & 3 & 3 \\
\hline & & & & 30 \\
\hline
\end{tabular}

Slika 4 - Primer evaluacije sprovedenih mera

\section{Zaključak}

ISO 9001:2015 opisuje rizik kao "odstupanje od očekivanog" bilo ono pozitivno ili negativno. Termin "neizvesnost" je objašnjen kao nedostatak informacija ili znanja o događaju koji se može pojaviti, kroz posledice i verovatnoću njegovog nastanka. C. Kymal, D. Reid [11] Kroz ovaj rad je objašnjen ceo tok aktivnosti koje treba preduzeti i značaj pravilnog sprovošenja svake od njih. 
Analiza rizika je osnova FMEA metode. Ova metoda predstavlja strukturirani pristup rizicima i tako pomaže projektantima sistema da razumeju ishode i prioritete čak i pre formalnog završetka analize rizika. K. Jenab, S. Khoury, S. Rodriguez [12] Uz kombinovanje sa drugim korisnim alatima za identifikaciju, upravljanje i preispitivanje rizika, FMEA može da pruži sveobuhvatno rešenje za zahteve koji se prožimaju kroz standard ISO 9001:2015.

Menadžment rizika, kao i menadžment kvaliteta je „put, a ne destinacija“ koji vodi do stalnog poboljšanja procesa poslovanja, od nastanka pojma kvaliteta pa sve do danas, a i ubuduće. M. Loosemore, J. Raftery [13] Procenjeni rizik u ponovnom ocenjivanju više ne mora da bude isti, a smanjeni neprihvatljivi rizik zbog nekog razloga može opet da poprimi neprihvatljivi nivo. To ima za posledicu da se kontinuirano mora sprovoditi menadžment rizika, a time i kontinuirano preduzimati aktivnosti da se rizici drže na prihvatljivom nivou. Prema prirodi problema, stalna kontrola i držanje rizika na prihvatljivom nivou je takođe poslovni proces i mnoge organizacije danas prepoznaju i primenjuju takav pristup u svom poslovanju. N. Čaušević, V. Peulić [14]

Može se zaključiti da se čitav proces menadžmenta rizika izložen u ovom radu, pored razmišljanja zasnovanog na riziku, oslanja na još jedan princip menadžmenta kvaliteta, a to je PDCA (Plan Do - Check - Act) ciklus. Na taj način se obezbeđuje povezanost zahteva standarda sa njegovim principima i stvara osnova za jedan funkcionalan i efikasan sistem koji omogućava stalna poboljšanja poslovanja organizacije.

Buduće verzije standarda će sigurno doneti još veći napredak u pristupu poslovnim rizicima. Sadašnji princip razmišljanja zasnovanog na rizicima, u sistemima menadžmenta kvaliteta, pruža odličnu osnovu za razvoj originalnih rešenja za razumevanje rizika i prostor za razvoj novih metoda i modela.

Rizici se mogu naći u zahtevima mnogih standarda za sisteme menaždmenta. Na primer, standard ISO 31000, iako nije namenjen sertifikaciji, pruža smernice za kompletan menadžment rizika. Oblast rizika će uvek biti aktuelna, jer ni jedna organizacija ne može da bude svesna svake neizvesnosti koje poslovanje nosi.

\section{$6 \quad$ Literatura}

[1] Vujošević, M. Upravljanje rizicima kao segment integrisanog sistema menadžmenta, Total Quality Management \& Excellence, 2008., broj 4, 2008.

[2] Đapić, M., Lj. Lukić, V. Kilibarda, Menadžment 2012, Međunarodna naučna konferencija, Univerzitet Union i Fakultet za poslovno industrijski menadžment, Beograd, Srbija, 2012.

[3] ISO 9001 history. The British Assessment Bureau, 2016. Dostupno na: british-assessment.co.uk. http://www.british-assessment.co.uk/iso-9001-history/

[4] Filipović, Jovan, Mladen Đurić, Sistem menadžmenta kvaliteta, Fakultet organizacionih nauka, Beograd, 2010.

[5] SRPS ISO 9001:2008 Sistemi menadžmenta kvalitetom - Zahtevi, Institut za standardizaciju Srbije, 2008.

[6] Francis, F., The good, the bad and the unsurprising. Quality World, 2009., broj 10, 2009.

[7] SRPS ISO 9001:2015 Sistemi menadžmenta kvalitetom - Zahtevi, Institut za standardizaciju Srbije, 2015.

[8] Vukčević, T., Z. Rajić. FMEA priručnik za praksu, Evropa Jugoinspekt, Beograd, 1994.

[9] Buntak, K., I. Drožđek, M. Košćak, Metodologija implementacije upravljanja rizicima FMEA metodom, Tehnički glasnik, 2014, broj 8, str. 25-33, 2014.

[10]Filipović, J., M. Đurić, Osnove kvaliteta, Fakultet organizacionih nauka, Beograd, 2009.

[11] Risk-Based Thinking and ISO 9001:2015, Kymal, C., D. Reid, Quality Digest, 2015. Dostupno na: qualitydigest.com. http://www.qualitydigest.com/inside/quality-insider-article/082115-riskbased-thinking-and-iso-90012015.html\#

[12] Jenab, K., S. Khoury, S. Rodriguez, Effective FMEA Analysis or Not?!, Strategic Management Quarterly, june 2015, broj 2, str. 25-36, 2015.

[13] Loosemore, M., J. Raftery, Risk management in projects, Taylor \& Francis, Njujork, 2006.

Čaušević, N., V. Peulić, Zbornik radova Proceedings, I Međunarodni naučni skup o ekonomskom razvoju i životnom standardu "EDASOL 2011 - Economic development and Standard of living", Panevropski Univerzitet, Banja Luka, 2011. 